\title{
AC 2011-1275: LIFELONG LEARNING AND INFORMATION LITERACY SKILLS AND THE FIRST YEAR ENGINEERING UNDERGRADUATE: REPORT OF A SELF-ASSESSMENT
}

\author{
Meagan C Ross, Purdue University, West Lafayette
}

\begin{abstract}
Meagan Ross is a Ph.D. student in the College of Engineering Education at Purdue University. She received a B.S. in Computer Science from Texas Woman's University, and a M.S. in Electrical Engineering from Texas Tech University. Prior to beginning her doctoral studies, she worked as a micro-optoelectromechanical systems engineer for Texas Instruments. Meagan began working for Institute for P-12 Engineering Research and Learning (INSPIRE) in the area of teacher professional development in 2009. Meagan is passionate about providing awareness of engineering to K-12 teachers \& counselors so that they can inform and advocate this important career to their students. Her research interests include gender equity in the K-12 Classroom, assessment of K-12 engineering education, curriculum development, and teacher professional development.
\end{abstract}

Michael Fosmire, Purdue University Libraries, West Lafayette

Ruth E. H. Wertz, Purdue University, West Lafayette

Ruth E. H. Wertz is a graduate student in Engineering Education at Purdue University. She is a Professional Engineer in the State of Indiana with her BS and MS degrees in Civil Engineering from Trine University and Purdue University.

\section{Dr. Monica E Cardella, Purdue University, West Lafayette}

Monica E. Cardella is an Assistant Professor of Engineering Education and is the Co-Director of Assessment Research for the Institute for P-12 Engineering Research and Learning (INSPIRE) at Purdue University. Dr. Cardella earned a B.Sc. in Mathematics from the University of Puget Sound and an M.S. and $\mathrm{Ph} . \mathrm{D}$. in Industrial Engineering at the University of Washington. At the University of Washington she worked with the Center for Engineering Learning and Teaching (CELT) and the LIFE Center (Learning in Informal and Formal Environments). She was a CASEE Postdoctoral Engineering Education Researcher at the Center for Design Research at Stanford before beginning her appointment at Purdue. Her research interests include: learning in informal and out-of-school time settings, pre-college engineering education, design thinking, mathematical thinking, and assessment research.

\section{Dr. Senay Purzer, Purdue University, West Lafayette}

Senay Purzer is an Assistant Professor in the School of Engineering Education and is the Co-Director of Assessment Research for the Institute for P-12 Engineering Research and Learning (INSPIRE) at Purdue University. Purzer has received her M.A. and Ph.D. degrees in Science Education at Arizona State University. She has a B.S. degree in Physics Education and a B.S.E. in Engineering. She has journal publications on instrument development, teacher professional development, and K-12 engineering education. Her creative research focuses on design problem-solving, collaborative learning, and assessment research.

(c)American Society for Engineering Education, 2011 


\section{Lifelong learning and information literacy skills and the first year engineering undergraduate: Report of a self-assessment}

\section{Introduction}

ABET accreditation requires engineering students to attain "a recognition of the need for and an ability to engage in lifelong learning.” (Outcome 3.i). ${ }^{\text {i }}$ Engineering Change ${ }^{\mathrm{ii}}$, a report of the effect of ABET's EC2000 program found a fifty percent or greater increase in design projects, open-ended problems, applications, case studies, and computer simulations, all of which typically require supplementary information to complete assignments successfully. However, comparing self-reports of outcomes for graduates from 1994 and 2004, the authors found lifelong learning (3.i) languished at the bottom of the list, with a 3.49 average out of 5 (almost all other outcomes average 3.9 or above), with almost no improvement over ten years (3.40 to 3.49). During the same time, for example, "global and societal issues" went from 2.95 to 3.65 (the next lowest rating to lifelong learning).

Despite the articulated need for (and apparent lack of progress teaching) lifelong learning skills, fairly little has actually been written about what comprises those skills and how to assess them. Shuman et al suggest that students be able to

- Demonstrate Reading, Writing, Listening, and Speaking Skills

- Demonstrate an Awareness of What Needs to be Learned

- Follow a Learning Plan

- Identify, Retrieve, and Organize Information

- Demonstrate Critical Thinking Skills

- Reflect on One's Own Understanding ${ }^{\text {iii }}$

Shuman's outcomes correlate well ${ }^{\text {iv }}$ with the ACRL Information Literacy standards for Science and Technology, which briefly are

- $\quad$ Determine the extent of information needed

- Access the needed information effectively and efficiently

- Evaluate information and its sources critically

- Incorporate selected information into one’s knowledge base

- Use information effectively to accomplish a specific purpose

- Understand the economic, legal, and social issues surrounding the use of information, and access and use information ethically and legally ${ }^{\mathrm{V}}$

Shuman's analysis also reflects the thinking of the self-directed learning community, ${ }^{\mathrm{vi}}$ and Cervaro ${ }^{\mathrm{vii}}$, for example, found that engineers engage in 'informal learning' activities, i.e., self-directed learning, much more frequently than formal learning activities, such as seminars and workshops.

In an instructional setting, one would like to understand the skills and attitudes of students, so appropriate content can be provided. Assessing these skills and attitudes often is time consuming, time that librarians don't have in a curricular setting. At the authors' institution, with over 1600 first-year engineering students, instructors struggle with providing detailed, timely, and individual feedback to students on topics as complex as information literacy. Consequently, the authors wanted to develop an easy to administer and easy to grade selfassessment to generate quick feedback on student attitudes. Further, the authors wanted to investigate whether results from the instrument correlate to performance on more authentic activities (such as report writing or design projects). 
Guglielmino viii developed the Self-Directed Learning Readiness Scale (SDLRS), a 58-question Likert scale selfassessment, which has been used by engineering educators ${ }^{\mathrm{ix}}$ to measure lifelong learning readiness. However, the SDLRS contains very little coverage of information gathering concepts, being limited to questions such as "I think libraries are boring places," and "if I discover a need for information that I don't have, I know where to go to get it." Recently, two research groups in nursing education created their own self-directed learning scales as well, which also provide little exploration of the informational component of lifelong learning. ${ }^{\mathrm{x}}$ Another instrument developed by Shinichi Monoi, Nancy O’Hanlon, and Karen R. Diaz ${ }^{\mathrm{xi}}$, on the other hand, uses a 12question instrument that focuses on specific strategies, such as 'I can construct a search using a Boolean operator,' and 'I can use the thesaurus in a database to select subject terms for a search,' which the authors felt was a little too library-centric for their purposes.

The authors thus believe there is room (and need) for the development of a similar scale to the SDLRS, but one focused on information skills, and a scale focused on actual behaviors and strategies rather than just attitudes. The scale elicits students' self-perception of how often they employ those skills.

\section{Method}

The study was conducted in the context of a foundation course at a large Midwestern university, which all freshman engineering students take. Students were required to complete the survey as a part of the course and the survey was administered online. The sample size for the study presented in this paper is $(\mathrm{N}=351)$. The data analysis for this paper is only descriptive in nature. Subsequent papers will do a formal factor analysis on the entire dataset $(\mathrm{N}>1600)$.

The specific competencies probed were generated from an analysis of different models of information gathering behaviors. The main input was the Information Search Process (ISP) of Carol Kuhlthau. ${ }^{\text {xi }}$ The ISP is a research-validated model of the stages an individual goes through when faced with a research task. It was developed in the context of typical 'research papers' that one might find in a humanities or social science course, so the authors modified and incorporated concepts extracted from engineering design process models and the authors' own analysis of previous student work. ${ }^{\text {xii }}$ From this analysis the authors decided to probe behaviors that include problem or task articulation, problem solving, information gathering, and the use, evaluation, and documentation of that information.

The authors narrowed down their original list of items to a compact instrument consisting of 26 questions probing nine difference concepts (see Table 1). Most concepts (6) have three associated questions, two concepts have two associated questions, and one concept has four. The questions were offered using a Likert Scale where 5 represented “Almost Always,” and 1 - “Almost Never.” There are no descriptors for 2-4, rather they suggested points on a continuum. All questions ask students to assess their own behaviors when faced with a research task (see Appendix), and were formulated by this team of researchers. 
Table 1 Categories Probed and Alignment with ISP Stages

\begin{tabular}{|l|l|}
\hline Assessment Categories & ISP Stages (Kuhlthau) \\
\hline Task definition and clarification (scoping) & Task Initiation \\
\cline { 1 - 1 } Creating a plan of action & \\
\hline Exploration of alternative solutions & Topic Selection \\
\hline Preliminary information gathering & Prefocus Exploration \\
\cline { 1 - 2 } Ability to locate information efficiently & \\
\hline Synthesis of Information & Information Selection \\
\hline Evaluation of information & \\
\hline Citation & Search Closure \\
\hline Reflection and Self-assessment & \\
\hline
\end{tabular}

\section{Analysis}

The overall mean of the student response was 4.05, as indicated by the dotted blue line in Figure 1 . This figure also shows each concept ranked from high to low (left to right) based on student responses. Each concept's mean is indicated by the horizontal purple lines. The blue lines connect the means for each individual question. Overall, students expressed high confidence levels in their information literacy skills, similar to the findings of Brown, et al. ${ }^{\text {xiv }}$ The assessment had a reliability coefficient (Chronbach’s alpha) of .98, and a preliminary factor analysis revealed a one-factor structure.

Figure 1: Means by Question, Concept, and Overall

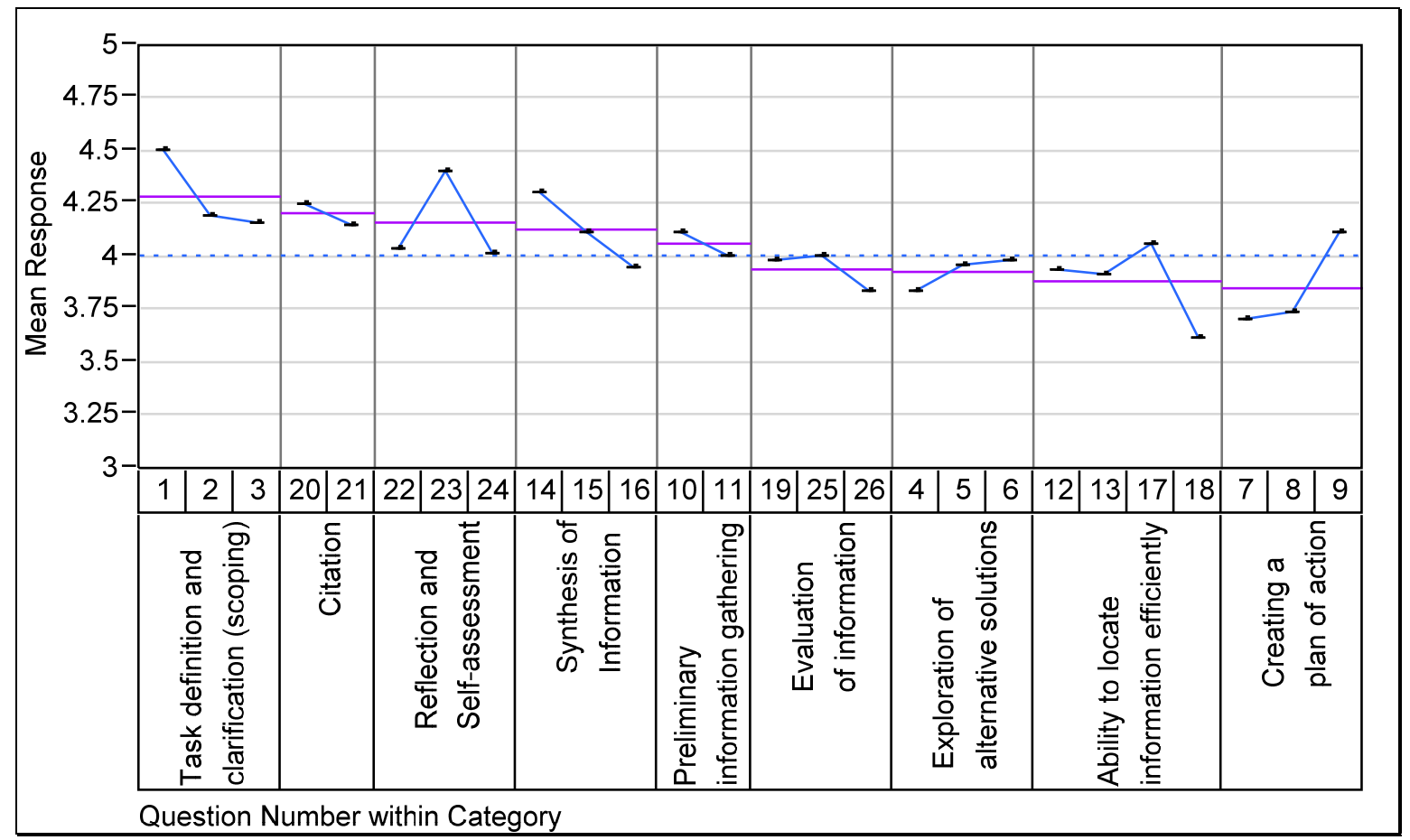

Students expressed high levels of confidence in their ability to define tasks, write correct citations, reflect on their performance, and synthesize information. Students expressed less confidence in their behaviors related to evaluating information, exploring alternative solutions, locating information efficiently, and creating plans of action. The areas students felt least confident with correspond to the initial stages of Kuhlthau's Information Search Process, that is, preliminary information searching and focus formation activities (see Table 1), in line with Kuhlthau's own findings in other student populations. ${ }^{\mathrm{xv}}$ Holliday and $\mathrm{Li}^{\mathrm{xvi}}$ have found that millennial 
students potentially skip more steps in the Information Search Process due to the easy access to information on the Internet, which leads to lower overall student performance and higher levels of frustration on student projects.

In a preliminary attempt to determine validity of the instrument, results of the self-assessment were correlated with an eight question multiple choice assessment ${ }^{\text {xvii }}$ students took that required students to read a memo and identify good and bad information usage. Figure 2 plots students' self-assessment scores (y-axis) against their grade on the multiple choice assessment (x-axis). The histograms show the density distribution of the plotted scores. The concentration of the scores does not show a significant correlation between the two assessments, although the highest self-assessments came from those who scored most poorly, and the students who scored the best on the multiple choice, rated themselves moderately in their overall self-assessment. This indicates, potentially, that students with greater knowledge of information literacy skills have more accurate selfperceptions of their abilities.

\section{Figure 2: Correlation of Student Self Assessment and Multiple Choice Responses}

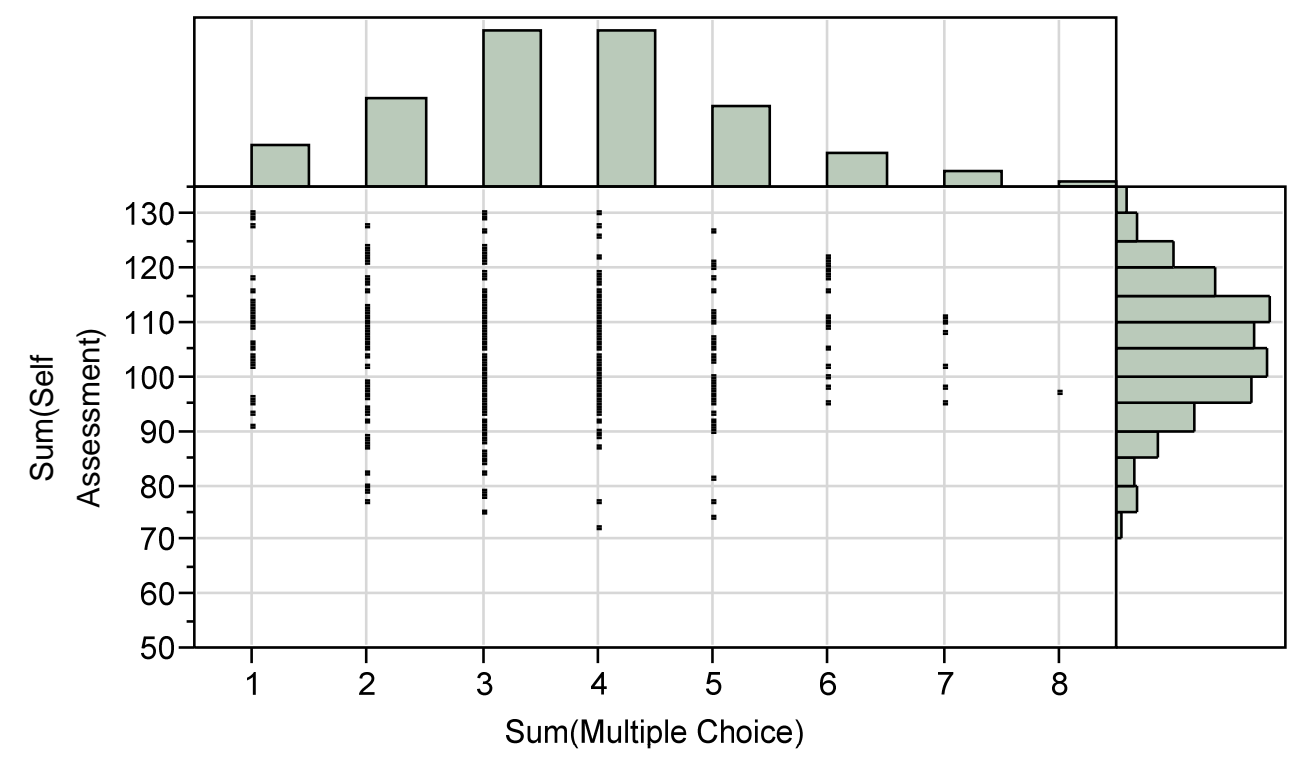

\section{Discussion}

Overall, students expressed less confidence in their ability both to find and to evaluate information than in the other concepts probed, while they reported documenting and citing sources as one of their most highly rated skills. However, comparing self-assessments with more direct measures of student performance (for example, analyzing the information component of student projects) yields a substantial 'novice effect' of inflated selfperception of competency. The higher achieving students had a more accurate self-knowledge of their skill levels, which indicates this tool might be more effective if given to a population of more advanced students, for example, at the junior level.

This initial analysis of the self-assessment tool was meant to guide revisions of the final instrument, exploring the concepts probed against student response. The correlation with the multiple choice assessment shows that student self-perception of information literacy competency is higher than their actual skill level. Further development of the instrument will attempt to circumvent the novice effect.

The implications of this research suggest that a self-assessment Likert scale instrument, such as the one discussed in this paper, may not be adequate as a stand-alone assessment of information literacy due to the inflated self-perceptions of competency. However, future work by this research team to develop a correlating factor between multiple instruments may provide a recommended adjustment scale in scoring a quick self-assessment of information literacy. The results, however, do indicate that students report less confidence in their abilities re- 
lated to the initial stages of the information gathering process, so care should be taken to include information literacy instruction which addresses that part of the information gathering cycle. The results indicate that students may need more assistance figuring out how to approach a problem and analyze competing solutions before diving into the research process. Since often information literacy instruction in engineering focuses on methods of locating resources (e.g., searching databases), this research indicates that a more holistic approach to information literacy is still warranted.

The authors will be conducting future studies to relate student self-perceptions to actual demonstrated behaviors (for example, student design projects) and to compare the results between first-year and upper-level undergraduates to determine how they change over the course of undergraduate study.

\section{Acknowledgements}

This research was carried out under IRB protocol \#1008009557, with financial support from the Purdue College of Engineering’s “Engineer of 2020 Seed Grant” program. 


\section{Appendix}

\section{Information Literacy Core Skills Self-Assessment}

5

$5=$ Always
4

3

2

1

$1=$ Never

\section{When faced with a new task (such as a design project) that I don't immediately know how to accomplish...}

1. I analyze the task to determine what needs to be done

2. I analyze the constraints of the task and not just the final deliverable

3. I seek clarification of the task expectations from those who want the task accomplished

4. I investigate how others have tackled the same or similar tasks in the past

5. I think of a variety of ways to accomplish the task before actually trying one

6. I compare the advantages and disadvantages of different approaches to solving the task

7. I create a list of resources/materials needed to complete the task

8. I create an action plan for completing the task on time and within other constraints

9. I determine what I know and what I need to find out about the task to complete it successfully

10. I collect information to become familiar with the concepts needed to carry out the task

11. I talk to others to gather a variety of perspectives and advice about the task

12. I efficiently and effectively locate information relevant to the task

13. I use search strategies to help focus the results I get from search engines and databases

14. I relate information I find to my pre-existing knowledge
15. I work to resolve conflicts between information I find and my pre-existing knowledge

16. I integrate information from a variety of sources to achieve a deeper understanding of a topic

17. I use the general information I find to help focus my search for more information

18. I know when to use different kinds of information (e.g., patents, standards, handbooks)

19. When gathering information, I assess the accuracy of information I find

20. When I present information, I acknowledge the source

21. When presenting information from a source, I use correct and complete citations

22. I test my solution against the original expectations of the task and revise my work to improve the solution

23. After I finish the task, I determine whether I completed it successfully

24. After I finish the task, I analyze my work to improve my performance on future tasks

25. When I gather information, I identify and use highquality sources

26. When I gather information, I evaluate the purpose of the source (for example, to persuade, inform, or entertain) when I decide whether and how to use it. 


\section{References}

\footnotetext{
${ }^{\mathrm{i}}$ ABET Engineering Accreditation Commission. 2010. Criteria for Accrediting Engineering Programs. Baltimore, MD: ABET. [http://www.abet.org/Linked\%20DocumentsUPDATE/Criteria\%20and\%20PP/E001\%2010-11\%20EAC\%20Criteria\%201-27-10.pdf]
}

ii Lisa R. Lattuca, Patrick T. Terenzini, and J. Fredricks Volkwein. 2006. Engineering Change: A Study of the Impact of EC2000. Baltimore, MD: ABET.

iii Shuman, L. J.; M. Besterfield-Sacre, and J. McGourty. 2005. "The ABET 'Professional Skills'-Can they be Taught? Can they be Assessed?" Journal of Engineering Education. 94 (1), 41-55.

iv Young, Sheila. 2007. ABET 3i: Lifelong Learning and Information Literacy . Presentation at the 2007 American Society for Engineering Education Annual Conference \& Exposition, Session 0241. http://depts.washington.edu/englib/eld/conf/07/ABET-3i-Sheila-Young.ppt

${ }^{v}$ Association of College and Research Libraries. 2000. Information Literacy Competency Standards for Higher Education. Chicago: ACRL, ALA.

${ }^{\mathrm{vi}}$ Knowles, M. S. 1975. Self-directed learning : a guide for learners and teachers. Cambridge Adult Education: Englewood Cliffs, NJ.

${ }^{\text {vii }}$ R.M. Cervero, J. D. Miller, and K.H. Dimmock. 1986. “The Formal and Informal Learning Activities of Practicing Engineers.” Engineering Education. 77(2): 112-114

viii Guglielmino, L. M. 1978. “Development of the Self-Directed Learning Readiness Scale.” Doctoral Dissertation, University of Georgia.

${ }^{\text {ix }}$ Litzinger, T., J. Wise, S. Lee, and S. Bjorkland. 2003. “Assessing readiness for self-directed learning.” Proceedings of the 2003 American Society for Engineering Education Annual Conference \& Exposition, Session 1330.

${ }^{x}$ Williamson, S. N. 2007. “Development of a self-rating scale of self-directed learning.” Nurse Researcher, 14(2):66-83. Fisher, M., King J, and Tague, G. 2001. "Development of a selfdirected learning readiness scale for nursing education.” Nurse Educator Today 21, 516525

${ }^{x i}$ Monoi, Shinichi, Nancy O’Hanlon, and Karen R. Diaz 2005. “Online Searching Skills: Development of an Inventory to Assess Self-Efficacy” Journal of Academic Librarianship, 31(2), 98-105. 
${ }^{\text {xii }}$ Kuhlthau, Carol.2004. Seeking Meaning: A Process Approach to Library and Information Services. Westport, CT: Libraries Unlimited.

xiii Wertz, Ruth, Meagan Ross, Michael Fosmire Senay Purzer, and Monica Cardella. 2011. "Do Students Gather Information to Inform Design Decisions? Development of an Authentic Assessment Tool of Information Gathering Skills in First-year Engineering Students.” In Proceedings of the ASEE National Conference, June 26-29, 2011 Vancouver, BC.

${ }^{\text {xiv }}$ Brown, C., T.J. Murphy, and M. Nanny. 2003. “Turning techno-savvy into info-savvy: authentically integrating information literacy into the college curriculum.” Journal of Academic Librarianship, 29(6), 386-98.

${ }^{\mathrm{xv}}$ Kuhlthau, ibid.

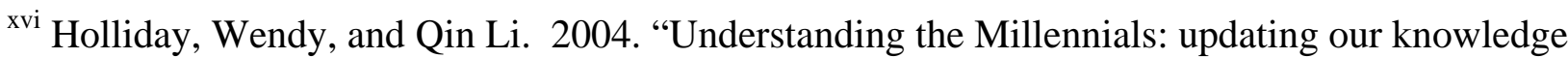
about students.” Reference Services Review 32(4), 356-366.

${ }^{x v i i}$ Purzer, Senay, Meagan Ross, Ruth Wertz, Michael Fosmire, and Monica Cardella. "Assessing Engineering Students' Information Literacy Skills: An Alpha Version of a MultipleChoice Instrument.” In Proceedings of the ASEE National Conference, June 26-29, 2011 Vancouver, BC. 